\title{
Presença de microrganismos indicadores de condições higiênicas, e de patógenos em bacalhau saithe (Pollacius virens) salgado seco, comercializado no município de Niterói, Rio de Janeiro, Brasil
}

\author{
Indigenous microrganisms and pathogens in saithe cod \\ (Pollacius virens) salty in retail of Niterói city, Rio de Janeiro, Brazil
}

\author{
Edivaldo S. de Almeida Filho, ${ }^{*}$ Cleise de Oliveira Sigarini, ${ }^{* *}$ Angélica M. Valente, ${ }^{* * *}$ Priscila Firmino Andrade, ${ }^{* * * *}$ \\ Luiz Antônio T. de Oliveira, Robson M. Franco, ${ }^{* * * *}$ José Carlos A. do Prado Carvalho*****
}

\begin{abstract}
Resumo
Peixes com a denominação bacalhau são bastante consumidos em nosso país, sendo importados e comercializados em mantas salgadas e secas. De todos os peixes conhecidos como bacalhau, o saithe (Pollacius virens) é um dos mais apreciados e mais consumidos, sobretudo por ser bastante acessível economicamente. Esse alimento é comercializado em temperatura ambiente e sem qualquer tipo de embalagem, favorecendo a contaminação por meio de manipulação inadequada e presença de vetores. O objetivo do presente estudo foi verificar a qualidade microbiana de bacalhau saithe salgado seco, comercializado no município de Niterói, RJ - Brasil, com relação a microrganismos indicadores de condições higiênico sanitárias, como coliformes fecais e Escherichia coli, e também de patógenos como Staphylococcus aureus e Salmonella spp. Não foi constatada a presença de coliformes fecais, e Staphylococcus aureus foi isolado em duas amostras $(6,66 \%)$, porém em contagens inferiores ao limite máximo permitido pela legislação brasileira. Com relação à pesquisa de Salmonella spp, duas amostras $(6,66 \%)$ revelaram a presença deste patógeno, o que as classifica como impróprias ao consumo. Das 30 amostras analisadas, $28(93,3 \%)$ se mostraram de acordo com a legislação vigente, sendo consideradas apropriadas ao consumo humano.
\end{abstract}

Palavras-chave: pescado salgado seco, microbiologia, bacalhau.

\begin{abstract}
Fishes with a denomination "cod" are very enjoyed in our country, being imported and trading in dry salted pieces. Among all fishes known "cod", the saithe fish (Pollacius virens) is one of the most appreciated and consumed because it economic accessibility. This product is treated in room temperature without packing protection, facilitating the contamination by inadequate manipulation and vectors presence. The objective of the present study was verify the microbiological quality of the saithe "cod" fish dry and slated, trading in Niterói, Rio de Janeiro state, Brazil, with relation the indicators microorganisms of hygiene and sanity conditions as fecal coliforms and Escherichia coli, and also pathogens like Staphylococcus aureus and Salmonella sp. It wasn't observed fecal coliform presence, and Staphylococcus aureus was isolated in 2 samples $(6,66 \%)$, however in counts lower than maximum limited permitted by the Brazil's law. About Salmonella sp. research, 2 samples $(6,66 \%)$ reveal the presence of this pathogen, what determine the classification "no consumption". Of the 30 samples analyzed, $28(93,3 \%)$ were in accord with the in force law so considered proper for the human consume.
\end{abstract}

Keywords: salted dry seafood, microbiology, saithe cod fish.

\section{Introdução}

O consumo de pescado tem crescido nos últimos anos, em virtude da busca, por parte do consumidor, de uma alimentação mais saudável e menos calórica (Almeida Filho, 2002). O Brasil produz anualmente cerca de 900 mil toneladas de pescado (Jornal Nacional, 2003). Segundo Germano e Germano (2001), em nosso país grande parte da produção interna se concentra na captura de espécies como sardinha (Sardinella brasiliensis), cação (Carcharynus spp), corvina (Micropogonias furnierì), camarão (Litopenaeus schimitti), lagosta (Palinurus argus), e atum (Thunnus thynnus). Outros tipos de pescado altamente apreciados são o salmão (Salmo salar) e o bacalhau. Em relação a este último, as principais espécies comercializadas com esta denominação são: Gadus mohua ou bacalhau verdadeiro, Pollacius virens, também conhecido como saithe, o Physiculus dalwigki, de nome popular ling, e Brosme brosme, conhecido como zarbo (São Paulo, 2003).

\footnotetext{
* Universidade Federal de Mato Grosso - UFMT - Brasil. Doutorando em Higiene e Tecnologia de Pescados e Derivados - Universidade Federal Fluminense - UFF.

** Secretaria de Saúde de Várzea Grande - MT - Brasil.

*** Mestranda em Higiene e Tecnologia de Pescados e Derivados - Universidade Federal Fluminense - Brasil;

**** Aluna de graduação em Medicina Veterinária - Universidade Federal Fluminense.

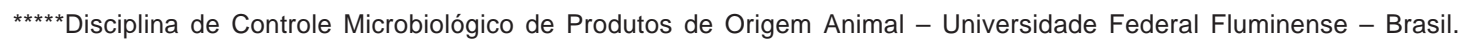


São importadas grandes quantidades anualmente, em virtude do bacalhau ser bastante apreciado por suas qualidades culinárias e nutritivas. Pertence à família dos Gadídeos e é o mais conhecido dos peixes de águas frias do Atlântico norte, no círculo polar ártico. O Brasil importa o bacalhau salgado seco, e cerca de $87 \%$ deste peixe consumido em nosso país tem sua origem na Noruega, mais precisamente na cidade de Aalesund (São Paulo, 2002).

O bacalhau é comercializado no Brasil em mantas salgadas e secas (Fig. 1), sendo armazenado em temperatura ambiente, o que permite sua distribuição em praticamente todo o território nacional. Segundo Connell (1988), a estabilidade de produtos salgados se obtém inibindo a ação de microrganismos e enzimas mediante uma alta concentração salina e uma desidratação considerável que acompanha o processo.

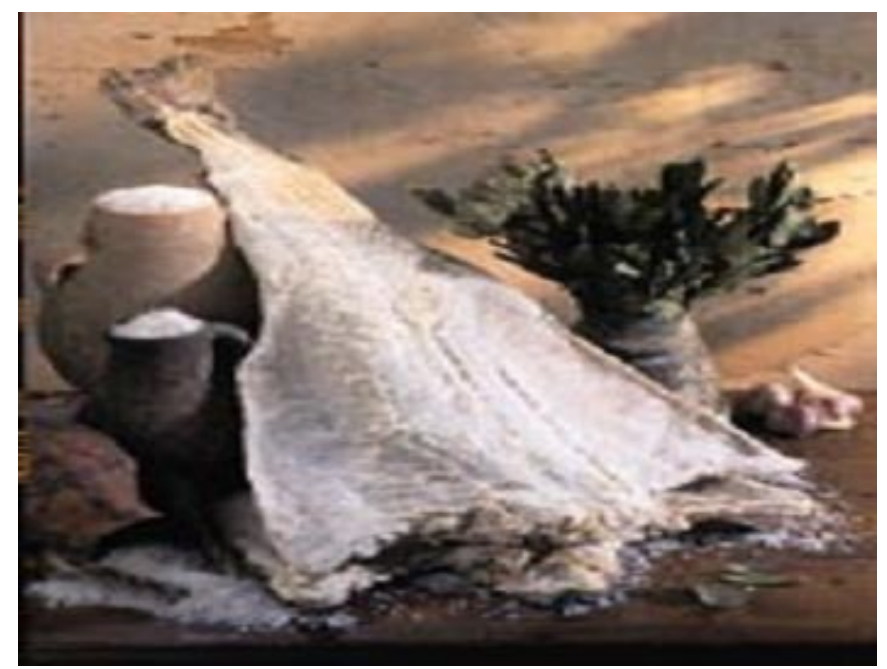

Figura 1: bacalhau salgado seco, comercializado em mantas

Dentre as espécies comercializadas com o nome bacalhau, o tipo saithe (Pollacius virens) é um dos mais apreciados (Fig. 2). É um peixe pelágico, que vive em profundidades de até 300 metros. É encontrado ao longo dos bancos litorais do mar do norte (Noruega, 2003). O saithe é um tipo mais escuro e de sabor mais forte, além de muito mais acessível ao público que o bacalhau verdadeiro. É utilizado para a confecção de bolinhos e ensopados de bacalhau, porque quando cozido sı c.arne desfia c.nm facilidade (Sãn Paıı ?กก३)

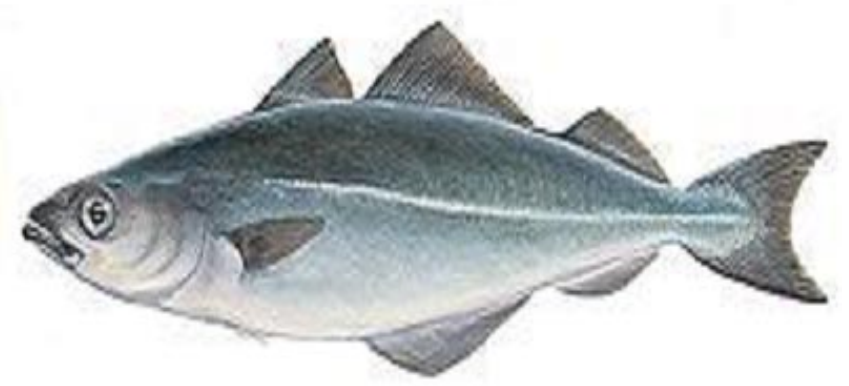

Figura 2: Bacalhau saithe (Pollachius virens) in natura

Apesar do pescado salgado seco possuir menor atividade de água, além do efeito inibidor do sal em relação à microbiota, se não houver critérios higiênico-sanitários ao longo da cadeia produtiva, poderá haver contaminação e sobrevivência de microrganismos indicadores de higiene, bem como patogênicos (Frazier e Westhoff, 1993). A legislação vigente em nosso país, a RDC no 12 (Brasil, 2001) estabelece os limites máximos permitidos para coliformes termotolerantes, Staphylococcus coagulase positiva, e Salmonella spp, e o objetivo do presente estudo foi verificar a qualidade bacteriológica do bacalhau saithe, salgado seco comercializado no município de Niterói, estado do Rio de Janeiro, Brasil, por meio da enumeração dos microrganismos supracitados.

\section{Material e métodos}

Foram colhidas 30 amostras de bacalhau salgado seco, durante os meses de agosto a outubro de 2002, em supermercados no município de Niterói, RJ. Imediatamente após a colheita, estas foram envolvidas em filme plástico impermeável e rapidamente enviados ao laboratório de Controle Microbiológico de Produtos de Origem Animal da Faculdade de Veterinária da Universidade Federal Fluminense - UFF, onde foram efetuadas as seguintes análises microbianas: contagem de Staphylococcus aureus, número mais provável de coliformes termotolerantes, número mais provável de Escherichia coli e pesquisa de Salmonella spp. As análises seguiram as recomendações da American Public Health Association (Downes e Ito, 2001).

\section{Resultados e discussão}

No quadro 1 encontram-se os resultados das 30 amostras analisadas de bacalhau saithe salgado seco, onde 28 (93,3\%) se mostraram de acordo com a legislação vigente (Brasil, 2001), sendo consideradas apropriadas ao consumo humano, como é confirmado no Gráfico 1.

Quanto à contagem de Staphylococcus aureus, das 30 amostras analisadas, duas delas (6,66\%) (Quadro 1) apresentaram-se contaminadas por este microrganismo, porém, em contagens inferiores ao máximo permitido pela legislação brasileira (Brasil, 2001). Este resultado encontrase em desacordo com os obtidos por Vilhelmsson et al. (1997), os quais constataram que a microbiota predominante em bacalhau salgado seco, comercializado na Finlândia era composta por bactérias do gênero Staphylococcus. Fernandes Vieira et al. (2002), analisando amostras de mapará (Hypophtalmus edentatus) salgado em Fortaleza, Brasil, não constatou a presença de Staphylococcus aureus em suas amostras, sendo que este resultado se aproxima do encontrado na presente pesquisa.

Quanto a pesquisa de Salmonella spp, em duas amostras $(6,66 \%)$ (Quadro 1) foi verificada a presença deste patógeno, o que coloca o alimento fora dos padrões da legislação brasileira, tornando-o impróprio ao consumo. Heinitz et al. (2000), por sua vez, estudando a presença de Salmonella spp em pescado salgado seco importado pelos Estados Unidos da América, em Minnesota, obteve $2,6 \%$ de positividade em suas amostras, resultado inferior ao encontrado no presente estudo.

A presença de Salmonella spp neste tipo de alimento revestese de grande importância sanitária em virtude do risco que o microrganismo representa, aliado ao próprio modo de preparo do pescado, que consiste primeiramente na eliminação do 
Quadro 1: Resultados das análises bacteriológicas de contagem de Staphylococcus aureus, número mais provável de coliformes termotolerantes, número mais provável de Escherichia coli, e pesquisa de Salmonella spp em bacalhau salgado seco.

\begin{tabular}{|c|c|c|c|c|}
\hline Amostra & Staphylococcus & $\begin{array}{c}\text { Salmonella } \\
\text { spp }\end{array}$ & Col. Term. & E. coli \\
\hline 1 & $<1,0 \times 10^{1}$ ufc/g & $(-)$ & $(-)$ & $(-)$ \\
\hline 2 & $<1,0 \times 10^{1} \mathrm{ufc} / \mathrm{g}$ & $(-)$ & $(-)$ & $(-)$ \\
\hline 3 & $<1,0 \times 10^{1}$ ufc/g & $(-)$ & $(-)$ & $(-)$ \\
\hline 4 & $<1,0 \times 10^{1} \mathrm{ufc} / \mathrm{g}$ & $(-)$ & $(-)$ & $(-)$ \\
\hline 5 & $<1,0 \times 10^{1} \mathrm{ufc} / \mathrm{g}$ & $(-)$ & $(-)$ & $(-)$ \\
\hline 6 & $<1,0 \times 10^{1}$ ufc/g & $(-)$ & $(-)$ & $(-)$ \\
\hline 7 & $<1,0 \times 10^{1}$ ufc/g & $(+)$ & $(-)$ & $(-)$ \\
\hline 8 & $<1,0 \times 10^{1} \mathrm{ufc} / \mathrm{g}$ & $(-)$ & $(-)$ & $(-)$ \\
\hline 9 & $<1,0 \times 10^{1}$ ufc/g & $(-)$ & $(-)$ & $(-)$ \\
\hline 10 & $<1,0 \times 10^{1}$ ufc/g & $(-)$ & $(-)$ & $(-)$ \\
\hline 11 & $<1,0 \times 10^{1}$ ufc/g & $(-)$ & $(-)$ & $(-)$ \\
\hline 12 & $<1,0 \times 10^{1}$ ufc/g & $(+)$ & $(-)$ & $(-)$ \\
\hline 13 & $7,0 \times 10^{2}$ ufc/g & $(-)$ & $(-)$ & $(-)$ \\
\hline 14 & $4,0 \times 10^{2} \mathrm{ufc} / \mathrm{g}$ & $(-)$ & $(-)$ & $(-)$ \\
\hline 15 & $<1,0 \times 10^{1}$ ufc/g & $(-)$ & $(-)$ & $(-)$ \\
\hline 16 & $<1,0 \times 10^{1}$ ufc/g & $(-)$ & $(-)$ & $(-)$ \\
\hline 17 & $<1,0 \times 10^{1}$ ufc/g & $(-)$ & $(-)$ & $(-)$ \\
\hline 18 & $<1,0 \times 10^{1}$ ufc/g & $(-)$ & $(-)$ & $(-)$ \\
\hline 19 & $<1,0 \times 10^{1}$ ufc/g & $(-)$ & $(-)$ & $(-)$ \\
\hline 20 & $<1,0 \times 10^{1}$ ufc/g & $(-)$ & $(-)$ & $(-)$ \\
\hline 21 & $<1,0 \times 10^{1}$ ufc/g & $(-)$ & $(-)$ & $(-)$ \\
\hline 22 & $<1,0 \times 10^{1}$ ufc/g & $(-)$ & $(-)$ & $(-)$ \\
\hline 23 & $<1,0 \times 10^{1}$ ufc/g & $(-)$ & $(-)$ & $(-)$ \\
\hline 24 & $<1,0 \times 10^{1}$ ufc/g & $(-)$ & $(-)$ & $(-)$ \\
\hline 25 & $<1,0 \times 10^{1}$ ufc/g & $(-)$ & $(-)$ & $(-)$ \\
\hline 26 & $<1,0 \times 10^{1}$ ufc/g & $(-)$ & $(-)$ & $(-)$ \\
\hline 27 & $<1,0 \times 10^{1} \mathrm{ufc} / \mathrm{g}$ & $(-)$ & $(-)$ & $(-)$ \\
\hline 28 & $<1,0 \times 10^{1}$ ufc/g & $(-)$ & $(-)$ & $(-)$ \\
\hline 29 & $<1,0 \times 10^{1}$ ufc/g & $(-)$ & $(-)$ & $(-)$ \\
\hline 30 & $<1,0 \times 10^{1}$ ufc/g & $(-)$ & $(-)$ & $(-)$ \\
\hline
\end{tabular}

excesso de sal por meio de imersão em água por algum tempo, o que pode proporcionar condições de crescimento da bactéria, agravado pela possibilidade de contaminação cruzada durante o preparo.

Não foi verificada a presença de coliformes termotolerantes e Escherichia coli nas amostras analisadas, o que pode ter sido

\section{Referências}

ALMEIDAFILHO, E. S.;SIGARINI, C.E.;RIBEIRO, J. N.;DELMONDES,E.C.; STELATTO, E.; ARAUJO Jr., A. Características microbiológicas de pintado (Pseudoplatystoma fasciatum) comercializado em supermercados e feira livre, no município de Cuiabá-MT. Rev Hig Alim. v. 16, n. 99, p. 84-88, 2002.

BRASIL, Ministério da Saúde, Agência Nacional de Vigilância Sanitária (ANVISA). Resolução RDC no 12, de 2 de janeiro de 2001. Aprova o regulamento técnico sobre padrões microbiológicos para alimentos. Disponível: www.agricultura.gov.br [acessado em 12 de julho de 2002]. CONNELL, J. J. Control de la calidad de pescado. Zaragoza: Acribia, 236 p.,1988.

DOWNES, P. D.; ITO, K. Compendium of methods for the microbiological examintaion of foods. 4th. ed. Washington: American Public Health Association (APHA), 2001.

FERNANDES VIEIRA, R. H. S.; BARROS, L. M. O.; SILVA, A .I. M.; TAKAKI, G. M. C. Qualidade microbiológica do mapará (Hypophtalmus edentatus) salgado, comercializado em Fortaleza, CE. Rev Hig. Alim., v. 15, n. 85 , p. 61-64, 2002.

FRAZIER, W. C.; WESTHOFF, D. C. Microbiología de los Alimentos. Zaragoza, Es: Editorial Acribia, 1993. 681 p.

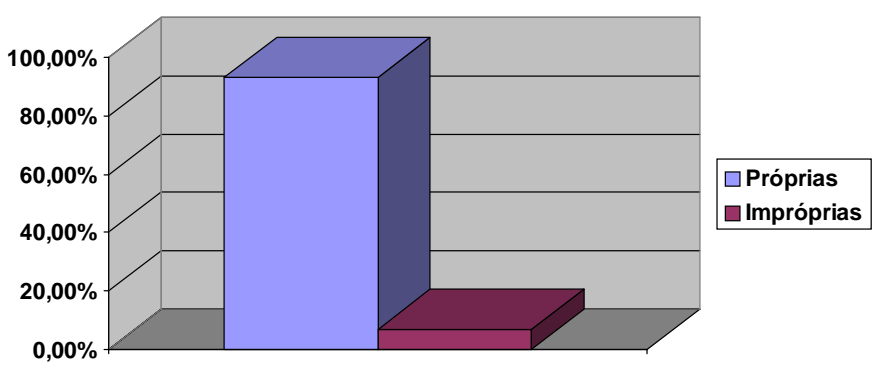

Gráfico 1: Porcentagem de amostras de bacalhau saithe consideradas próprias e impróprias ao consumo (Brasil, 2001).

o resultado da ação inibitória do sal e da baixa atividade de água sobre estes microrganismos.

O objetivo da escolha dos microrganismos pesquisados foi avaliar as condições higiênico-sanitárias das amostras, uma vez que estas são submetidas a intensos procedimentos de manipulação sem as devidas condições higiênicas, além de ficarem expostas em ambientes não refrigerados, não serem embaladas e sofrerem o ataque de pragas como moscas. Além dos motivos supracitados, outra justificativa foi a existência de padrões oficiais na legislação vigente para todos os microrganismos analisados.

\section{Conclusões}

Das 30 amostras analisadas, duas (6,66\%) apresentaram-se contaminadas por Salmonella spp, sendo, portanto, consideradas impróprias para o consumo humano.

Em duas amostras $(6,66 \%)$ foram verificadas contagens de Staphylococcus aureus, porém com resultados abaixo do limite máximo permitido pela legislação oficial.

Não foi verificada a presença de coliformes termotolerantes, bem como Escherichia coli em nenhuma das amostras.

Ao todo, 28 amostras $(93,3 \%)$ se mostraram de acordo com a legislação vigente, sendo consideradas apropriadas ao consumo humano segundo a legislação brasileira.

GERMANO, P. M. L.; GERMANO, M. I. S. Higiene e vigilância sanitária de alimentos. São Paulo: Varela, 2001.

HEINITZ, M. L.; RUBLE, R. D.; WAGNER, D. E.; TATINI, S. R. Incidence of Salmonella spp in fish and seafood. Journal of Food Protection, v. 65, n. 5, p. 579-592, 2000.

JORNAL NACIONAL. A pesca no Brasil. Disponível: www.globo.com/ jornalnacional [acessado em 3 de fevereiro de 2003].

NASCIMENTO, A.R.; FILHO, J. E. M.; TATY, S. R. Pesquisa de coliformes e Staphylococcus enteropatogênicos em camarões salgados secos comercializados nos mercados e feiras livres de São Luís-MA. Rev Hig. Alim., v. 15, n. 85, p. 65-68, 2002.

NORUEGA. Treasures of the sea. Seafood from Norway. Disponível: www.seafood.no [acessado em 3 de Fevereiro de 2003].

SÃO PAULO. Cod - O príncipe dos mares do norte. Disponível: www.bacalhau.com.br [acessado em 24 de novembro de 2002].

SÃO PAULO. Tipos e características do bacalhau. Disponível: www.bacalhau.com.br [acessado em 3 de fevereiro de 2003].

VILHELMSSON, O.; HAFSTEISSON, H.; KRISTJANSSON, J. K. Extremely halotolerant bacteria characteristic of fully cured and dried cod. International Journal of Food Microbiology, v. 20-36, n. 2-3, p. 163170, 1997. 